\title{
Role Modeling Clinical Judgment for an Unfolding Older Adult Simulation
}

\author{
Kathie Lasater \\ Oregon Health and Science University \\ Elizabeth A. Johnson \\ Ball State University \\ Patricia K. Ravert \\ Brigham Young University - Provo, patricia-ravert@byu.edu \\ Doris Rink \\ Portland Community College
}

Follow this and additional works at: https://scholarsarchive.byu.edu/facpub

Part of the Other Nursing Commons

\section{Original Publication Citation}

Lasater, K., Johnson, E., Ravert, P., \& Rink, D. (2014). Role-modeling clinical judgment for an unfolding older adult simulation. Journal of Nursing Education. 53(5), 257-264.

\section{BYU ScholarsArchive Citation}

Lasater, Kathie; Johnson, Elizabeth A.; Ravert, Patricia K.; and Rink, Doris, "Role Modeling Clinical Judgment for an Unfolding Older Adult Simulation" (2014). Faculty Publications. 5282.

https://scholarsarchive.byu.edu/facpub/5282 


\title{
Role Modeling Clinical Judgment for an Unfolding Older Adult Simulation
}

\author{
Kathie Lasater, EdD, RN, ANEF; Elizabeth A. Johnson, PhD, RN; \\ Patricia Ravert, PhD, RN, FAAN, ANEF; and Doris Rink, MSN, RN
}

\begin{abstract}
Nurse educators must foster development of clinical judgment in students to help them provide the best care for the increasing population of older adult patients. This article reports qualitative findings from a mixed-methods study that focused on clinical judgment in the simulated perioperative care of an older adult. The sample was composed of treatment and control groups of prelicensure students $(N=275)$ at five sites. The treatment group watched a video of an expert nurse role model caring for a patient similar to the simulation patient, whereas the control group did not watch the video. Four weeks after simulation, participants cared for real-life, older adult perioperative patients. After the simulated and real-life care experiences, participants completed questionnaires related to clinical judgment dimensions. These two data sets revealed rich findings about the students' simulation learning, affirming the value of expert role models. Transferability of simulation learning to practice was also explored. [J Nurs Educ. 2014;53(5):257-264.]
\end{abstract}

Received: June 24, 2013

Accepted: December 3, 2013

Posted Online: April 14, 2014

Dr. Lasater is Associate Professor, School of Nursing, Oregon Health \& Science University; Ms. Rink is Simulation Coordinator Nursing Faculty, Portland Community College Sylvania Campus, Portland, Oregon; Dr. Johnson is Assistant Professor, Ball State University, Muncie, Indiana; and Dr. Ravert is Dean and Professor, Brigham Young University, Provo, Utah.

Partial funding for this research was provided by a National League for Nursing Research in Education grant.

The authors have disclosed no potential conflicts of interest, financial or otherwise.

Address correspondence to Kathie Lasater, EdD, RN, ANEF, Associate Professor, School of Nursing, Oregon Health \& Science University, 3455 SW Veterans' Hospital Road, \#SN-4S, Portland, OR 97239; e-mail: lasaterk@ohsu.edu.

doi:10.3928/01484834-20140414-01
$\mathrm{T}$ The older adult population is expected to comprise $19.3 \%$ of the total U.S. population by 2030, which is an increase from $15 \%$ in 2010 (Werner, 2011). Until that time, it is estimated that 10,000 Americans will reach the age of $65 \mathrm{ev-}$ ery day (Cohn \& Taylor, 2010), and nurses will provide care to older adults at a time when a worldwide nursing shortage is predicted (Wilson \& Fowler, 2012). Consequently, today's students will be the future nurses providing this care; thus, it is imperative to prepare them to care for older adults.

Simulation is a growing pedagogical strategy to provide a range or quantity of experiences that students may not be exposed to in clinical practice settings (American Association of Colleges of Nursing, 2012). Although simulation research has burgeoned in the past decade, challenges still exist. These include, but are not limited to, inconsistent approaches (Cant \& Cooper, 2010; Lewis, Strachan, \& Smith, 2012); small groups of participants at individual sites, which limit generalizability of findings; whether simulation can facilitate competence in nontechnical skills; and the impact of expert nurse role models on simulation performance.

An international, multisite study was undertaken to address these challenges. The first part of the study was a three-phase, unfolding older adult patient simulation. Each phase required participants to utilize clinical judgment to manage the patient's care. The definition of clinical judgment was, "an interpretation or conclusion about a patient's needs, concerns, or health problems, and/or the decision to take action (or not), use or modify standard approaches, or improvise new ones as deemed appropriate by the patient's response" (Tanner, 2006, p. 204). The second part of the study focused on the care of a similar, real-life patient 4 weeks after the simulation. The aims of the study were to (a) examine the effect of an expert nurse role model on student clinical judgment in simulation and (b) explore whether clinical judgment skills transfer to the clinical setting. The purpose of this article is to report the qualitative findings from the study.

\section{THEORETICAL BACKGROUND}

Evidence to support the practice of using medium- to highfidelity manikin simulators as an effective pedagogical strategy 
was presented in a systematic review of simulation in health care education (Cant \& Cooper, 2010). However, the lack of studies investigating the outcomes of simulation, including the transfer of learning from simulation to clinical settings, and patient outcomes has created a significant gap (Cant \& Cooper, 2010; Rutherford-Hemming, 2012).

In an analysis of the pedagogical underpinnings of simulation, Anderson, Aylor, and Leonard (2008) demonstrated the use of an expert exemplar to deepen student learning. This approach is consistent with the concepts of observational learning and mastery modeling, described in Bandura's social cognitive theory $(1986,1997)$, and may provide a theoretical bridge from simulation to the bedside. Observation of an expert model initiates a process by which learners observe decisionmaking strategies, transform those observations into mental symbols, and later produce behaviors from what is recalled (Bandura, 1997). The expectation that modeled behaviors are required to manage future situations increases the attention paid to the model (Bandura, 1986). To develop mastery, behaviors are practiced in a safe environment before transferring the behavior to an actual work environment (Bandura, 1997). Simulation learning as experiential pedagogy supports these concepts. Bandura's work formed the basis for examining the use and impact of an expert nurse role model for students learning to care for older adults with perioperative needs in a simulation setting.

The Tanner (2006) model of clinical judgment is the theoretical framework used in the current study for evaluating clinical judgment. Tanner identified four critical aspects of clinical reasoning that are involved in making the best clinical judgments for patients with complex issues-noticing, interpreting, responding, and reflecting. Tanner further described the situated nature of clinical judgment; that is, the context of care, the background of the nurse, and the relationship of the nurse with the patient will influence what the nurse notices.

\section{METHOD}

\section{Study Sample}

Four diverse U.S. sites and one site in the United Kingdom were all philosophically in agreement with the definition of clinical judgment (Tanner, 2006) and used the model. The institutional review boards of each of the five sites approved the study. At each site, participants were enrolled in the first clinical course offered that focused on care of perioperative patients. Students were required to participate in the simulations as part of the course, but they could opt to withhold their data from the study. Using the same protocols at each site provided a consistent approach. Before the simulation experience, half of the students at each site observed a video of an expert nurse role model caring for a similar simulated patient (treatment group). The other half of the students did not have this exposure (control group). Participants across all sites totaled 275, offering confirmability of findings.

\section{Study Design}

It was determined that a mixed-methods design would best serve the purposes of the study. A full description of the three- phase unfolding simulation scenario, protocols, and quantitative findings appeared in previous articles (Johnson et al., 2012; Lasater, Johnson, Hodson-Carlton, Siktberg, \& Sideras, 2012). To summarize, experienced simulation faculty designed a threephase simulation centered on the care of an older adult female, fictitiously named Martha Gorski, who had fallen and broken her hip. The three phases included (a) admission to the preoperative unit, (b) admission to the postoperative surgical unit, and (c) 2 days postoperatively, as the patient was showing signs of delirium. Quantitative data were composed of direct measurement of the four aspects of clinical judgment, as defined by Tanner (2006). Those findings revealed a statistically significant difference $(p<0.001)$, favoring the treatment group in three of the four aspects of clinical judgment. However, simulation engages students in different ways (Lasater, 2007a), so exploring whether the participants' lived experiences (qualitative) in viewing an expert nurse role model patient care impacted their learning from simulation was an important contrast to the quantitative findings.

All participants underwent the same preparation and debriefing procedures. When the participants were assigned to the control or treatment groups at each site, they randomly drew cards to determine in which of the three simulation phases they would participate; those not directly involved in the scenario were active observers and contributed to debriefings.

\section{Qualitative Data Collection and Instruments}

Two data sets comprised the qualitative data: postsimulation and postcare. Qualitative data were used to validate or expand the quantitative findings. For both qualitative data sets, participants answered 11 open-ended questions (Table), based on dimensions from the Lasater (2007b) Clinical Judgment Rubric $^{\odot}$. Lasater developed evidence-based dimensions to enlarge the meaning of Tanner's (2006) aspects of effective clinical reasoning - noticing, interpreting, responding, and reflecting. Four levels, with descriptors for each of the 11 dimensions, allow for scoring or for description of performance. For the postsimulation data, participants completed the questionnaire online immediately after their simulation experiences; a unique identifier protected each participant's identity.

The postcare data were collected 4 weeks after the simulation when a subset of the original participants cared for older adult perioperative patients at their clinical practice sites. These participants completed a similar questionnaire, plus one additional question (Table). The questions were reformatted slightly to address the change from the simulated patient to real-life patients, whose names and specific diagnoses were unknown. The added question for this postcare dataset asked participants whether their simulation experiences had informed their care (yes or no) and to explain their answers.

One limitation of the study was the inability of the program in the United Kingdom to participate in the postcare data collection due to timing. Also, some participants of the postsimulation group did not have the opportunity to care for an older adult perioperative patient at the 4-week mark. An additional limitation was that one site inadvertently posted the postsimulation questionnaire without the added question. These combined factors resulted in a smaller postcare sample. 
TABLE

Questionnaires for Qualitative Data Collection

\begin{tabular}{|c|c|c|c|}
\hline $\begin{array}{l}\text { Aspect of Tanner } \\
\text { (2006) Model of } \\
\text { Clinical Judgment }\end{array}$ & $\begin{array}{l}\text { LCJR Dimension } \\
\text { (Lasater, 2007) }\end{array}$ & Postsimulation Reflective Question & Postcare Reflective Question \\
\hline \multirow[t]{3}{*}{ Effective noticing } & Focused observation & What did you notice first about Martha? & $\begin{array}{l}\text { What did you notice first about your } \\
\text { surgery patient? }\end{array}$ \\
\hline & $\begin{array}{l}\text { Recognizing deviations } \\
\text { from expected patterns }\end{array}$ & $\begin{array}{l}\text { How was this different than what you } \\
\text { expected? }\end{array}$ & $\begin{array}{l}\text { How was this different than what you } \\
\text { expected? }\end{array}$ \\
\hline & Information seeking & $\begin{array}{l}\text { What other information would have been } \\
\text { helpful in caring for Martha? }\end{array}$ & $\begin{array}{l}\text { What other information would have been } \\
\text { helpful in caring for your patient? }\end{array}$ \\
\hline \multirow[t]{2}{*}{ Effective interpreting } & Prioritizing data & $\begin{array}{l}\text { What one aspect of Martha's care did you } \\
\text { judge was the most important to address? }\end{array}$ & $\begin{array}{l}\text { What one aspect of your patient's care } \\
\text { did you judge was the most important to } \\
\text { address? }\end{array}$ \\
\hline & Making sense of data & $\begin{array}{l}\text { What past learning helped you to determine } \\
\text { Martha's needs? }\end{array}$ & $\begin{array}{l}\text { What past learning helped you to } \\
\text { determine the patient's need? }\end{array}$ \\
\hline \multirow[t]{4}{*}{ Effective responding } & Calm or confident manner & $\begin{array}{l}\text { On a scale of } 1 \text { to } 10 \text {, with } 1 \text { being the lowest } \\
\text { and } 10 \text { being the highest, how calm or } \\
\text { confident did you feel in caring for Martha? } \\
\text { Why? }\end{array}$ & $\begin{array}{l}\text { On a scale of } 1 \text { to } 10 \text {, with } 1 \text { being the } \\
\text { lowest and } 10 \text { being the highest, how } \\
\text { calm or confident did you feel in caring } \\
\text { for your patient? Why? }\end{array}$ \\
\hline & Clear communication & $\begin{array}{l}\text { Give a one-sentence example of your best } \\
\text { communication with Martha. }\end{array}$ & $\begin{array}{l}\text { Give a one-sentence example of your } \\
\text { best communication with your patient. }\end{array}$ \\
\hline & $\begin{array}{l}\text { Well-planned intervention; } \\
\text { flexibility }\end{array}$ & $\begin{array}{l}\text { What were the two most important factors } \\
\text { that impacted your intervention for Martha? }\end{array}$ & $\begin{array}{l}\text { What were the two most important } \\
\text { factors that impacted your intervention } \\
\text { for your patient? }\end{array}$ \\
\hline & Being skillful & $\begin{array}{l}\text { How do you think your care for Martha } \\
\text { compared with the expected care? }\end{array}$ & $\begin{array}{l}\text { How do you think your care for your } \\
\text { patient compared with the expected } \\
\text { care? }\end{array}$ \\
\hline \multirow[t]{3}{*}{ Effective reflecting } & $\begin{array}{l}\text { Evaluation and self- } \\
\text { analysis }\end{array}$ & $\begin{array}{l}\text { What was the most effective decision you } \\
\text { made for Martha? What was the worst, if any? }\end{array}$ & $\begin{array}{l}\text { What was the most effective decision } \\
\text { you made for your patient? What was the } \\
\text { worst, if any? }\end{array}$ \\
\hline & $\begin{array}{l}\text { Commitment to } \\
\text { improvement }\end{array}$ & $\begin{array}{l}\text { What would you do differently in this case if } \\
\text { you had the opportunity? }\end{array}$ & $\begin{array}{l}\text { What would you do differently in this } \\
\text { case if you had the opportunity? }\end{array}$ \\
\hline & Transfer of learning & & $\begin{array}{l}\text { Do you believe your care of Martha } \\
\text { Gorski in the hip fracture-delirium } \\
\text { simulation } 4 \text { weeks ago better prepared } \\
\text { you to care for your surgery patient in the } \\
\text { clinical setting? Explain. }\end{array}$ \\
\hline
\end{tabular}

Note. LCJR = Lasater Clinical Judgment Rubric. Copyright 2007 by Kathie Lasater, EdD, RN, ANEF.

\section{Data Analysis}

The 11 dimensions from the Lasater (2007b) Clinical Judgment Rubric were used as codes for entering the qualitative data in the NVivo 7.0 software program. The added question for the postcare dataset became the 12th code-Transfer of Learning. Hsieh and Shannon (2005) described this strategy as directed content analysis. Every participant's full responses were coded, ensuring thick, rich text from two data sets for analysis. When the data were entered, the aggregated data were sorted by each of the 11 or 12 codes. The authors, one from each U.S. site, reviewed the data, using both thematic and content methods to analyze the aggregated data at frequent group meetings held via telephone over a 3-month period; each author then verified the themes. No attempt was made to correlate individual responses with both data sets or to analyze participant responses by site. Patton (1999) described multiple data sources, analysts, and perspectives and theories, all present in this study, as triangulation that offers consistency and confirmability.

\section{FINDINGS AND DISCUSSION}

Two hundred seventy-five participants formed the postsimulation sample; of these, 221 were from the United States 
and 54 were from the United Kingdom. The postcare sample included 134 U.S. participants. To approach the analysis and report the data, the findings are conveyed in three categories: (a) general findings, (b) postsimulation, and (c) postcare. Appropriate literature is discussed in each section to minimize confusion.

\section{General Findings}

Participants across treatment and control and postsimulation and postcare groups were generally consistent in their ability to notice and identify the main patient issues-pain, respiratory management, delirium, and patient safety. However, they were not always as effective in knowing how to interpret or respond to the issues. For example, even though the treatment group participants viewed the expert nurse role model video, their responses indicated surprise at the severity of the delirium phase. Several subthemes emerged in this category: (a) the developmental stage of these learners, (b) how they think about their thinking, and (c) their view of older adult patients.

Developmental Stage. Participants were not yet halfway through their programs. Frequent comments about being observed were representative of their insecurity about their skills (e.g., how to act on the outcomes of their patient assessments). This is congruent with the findings by others (Cordeau, 2010; Lasater, 2007a), including Suliman and Halabi (2007) who found that anxiety in nursing students was negatively related to critical thinking skills and lack of experience represented by students early in program.

In addition, many participants noted that coping with family and other health care team members added complexity, which they did not feel skilled to handle. One participant described family members as a distraction:

I felt that I knew how to assess her [the patient] and kind of

what to look for; however, I felt flustered with the family member asking so many questions. I forgot to check some stuff that I wanted to and didn't have as structured an assessment.

Participants often identified that their communication with families or with other health care team members was among their poorest performances, perhaps related to anxiety, lack of experience, or a combination of both.

Another developmental issue that emerged was not knowing which patient information items were most important. Benner, Sutphen, Leonard, and Day (2010) referred to this as salience. Participants frequently reported that they expected to receive more information than they did. The most common examples were psychosocial descriptions of Martha and her family members and other health history data related to previous surgical experiences and postoperative pain. Yet, most participants answered that they had enough information to care for Martha (Table, Information Seeking). Few participants asked questions about Martha or clarified information they were given. Knowing what to ask or how to ask the right questions is predicated on understanding the issues; however, inability to grasp the situation enough to ask appropriate questions is not unusual in novice nurses (Benner, 1984; Benner, Tanner, \& Chesla, 2009).

The authors expected the treatment group to mention the expert nurse role model from the video; however, an unexpected finding was the number of references by the control group to nurses providing care in clinical situations, thereby extending our perception of expert role modeling. Coincidentally, participants frequently mentioned classroom learning, as well as clinical experiences, as being more helpful to care for their reallife patients than assigned readings. This raises questions about their knowledge synthesis and application from what they read to higher order thinking skills. It underscores the observation by Benner et al. (2010) that inexperienced students may require more explicit guidance to connect theory with practice to develop their sense of salience. Other research offered that simulation has the capacity to bridge theory with clinical experience to uncover gaps and to focus on what is important (Lasater, 2007a).

Thinking. Generally, the responses of both groups were short, somewhat vague, and focused on tasks, although the postsimulation treatment group generally reported a more holistic picture of Martha's needs, particularly in the aspect of noticing. The treatment group's exposure to an expert role model may have opened up their thinking, enabling them to more fully grasp the situation (Tanner, 2006). Mastery modeling operates through a normative function, providing basic rules and strategies that allow learners to acquire problem-solving skills and may increase learner self-efficacy related to their ability to control thought processes (Bandura, 1986, 1997).

Participants in both groups were generally unaware of how to evaluate their nursing care or lacked an evidence-based framework for care. For example, one question focused on comparing their care to expected care (Table, Being Skillful). Many participants responded positively about their level of care; yet, on a later question (Table, Commitment to Improvement), they quickly identified major aspects of care they would change. For example, one control group participant initially said, "I think that our group did a pretty good job of caring for Martha," then later said:

One of the things that I know I really need to work on is communication. I became intimidated in the simulation and didn't really know what I was supposed to be doing, and I think that problem could have been solved by communicating with the

other nurses.

Standards of care or care planning were rarely referenced; answers reflected more on perceptions about care than on knowledge or evidence. Participants may have thought their care was adequate for their level, but it was clear they did not know on what to base their assessments. This has implications for student ability to prioritize patient needs and, most likely, represents their stage of development.

View of Older Adults. Participants conveyed stereotypical views about older adults, reflective of a broader, negative societal perspective on aging. For example, some participants expected to find the patient confused and disoriented, even before surgery. One participant focused attention on the family instead of on the patient. A participant's comment about a real-life patient reflected a judgmental attitude, "[I] first noticed that the patient's behavior [was] not appropriate for her age...demanding, always needs attention from relatives."

Consistent with disengagement theory, young adults often view late adulthood as an unproductive time during which individuals isolate themselves from the community (Wurtele, 2009). This perspective, also found in the disciplines that 
inform nursing, contributes to a stereotype of dependency (Phelan, 2011).

Ageism affects the number of health care providers who have the skills needed for an increasingly aged population (Heise, Johnsen, Himes, \& Wing, 2012). When societal views reinforce a negative attitude toward older adults, it can be difficult to shift student attitudes (Aud, Bostick, Marek, \& McDaniel, 2006). Koren et al. (2008) found nursing student attitudes to be neutral toward older adults and that they positively correlated with comfort and confidence in caring for older adults. Anxiety about one's own aging process was also significantly correlated with ageism (Allan \& Johnson, 2008). This anxiety mediates the relationship between knowledge and attitude. When attitudes are positive, students can more confidently care for older patients. Two participant narratives demonstrate how simulation encouraged awareness and positive attitudes about the special needs of older adults. After the simulation, one participant remarked:

[It] was a good reminder of how intense the everyday nursing experience can be and how accustomed we become to caring for postoperative patients in a blanket way. [We need to pay] more attention to the individual.

After caring for her real-life patient, another participant said:

I was concerned that [staff] wouldn't deal as well as they should, mostly because of the patient's age. As a result of being flat on his back during surgery with no regard to his particular need, the patient woke up in the PACU [postanesthesia care unit] in an extreme amount of discomfort.

\section{Postsimulation Findings}

The postsimulation data set revealed the most dramatic differences between the treatment and control groups. The differences clustered on knowing what to expect and increased confidence.

Knowing What to Expect. Both the treatment and control groups had minimal background in nursing and had the same preparation for the simulation. According to some researchers, deep knowledge is foundational for clinical judgment (Benner et al., 2009; Bransford, Brown, \& Cocking, 2000). The treatment group's observation of an expert role model may have contributed to their deeper knowledge. One treatment group participant said:

When I have a baseline of knowledge to draw from and an opportunity to observe a professional nurse's decision making beforehand, I feel better able to provide quality care than if I hadn't thought through my priorities of care and my role in the scenario.

It could be argued that observing an expert nurse role model before simulation might explain participant understanding of patient needs. But observation is only the beginning and must be followed with role rehearsal, practice, and informative feedback to perfect new skills (Bandura, 1997). Simulation followed by careful patient assignment in the clinical area provides these elements. One treatment group participant explained:

I didn't feel nervous going into the scenario and knowing what was coming, but then being in the room and actually having to deal with the problems made my anxiety increase. I feel like I knew what needed to be done and how, but the part I need practice with is implementing the care and making sure I'm always critically thinking to know what should come next.
Knowing what to expect seems to correlate with practical experience (Benner et al., 2009). Consistent with Bandura's (1997) mastery modeling, the expert nurse role model provided the treatment group with an understanding of what to expect, thereby expanding their experience. One treatment group participant described the impact of the expert nurse role model on his or her expectations:

I felt a lot more comfortable about what to expect after seeing that video. If I had gone in just with reading the articles, I wouldn't have felt as confident. I also have no previous experience with settings like this. Personally, I like to know as much as I can ahead of time and what to expect in all situations.

Increased Confidence. Self-reported increases in confidence after simulation have been identified in other studies (Bambini, Washburn, \& Perkins, 2009; Blum, Borglund, \& Parcells, 2010; Bremner, Aduddell, \& Amason, 2008; Kaplan \& Ura, 2010). In the current study, participants in the treatment group reported higher self-rankings of confidence than the control group. Participants were asked to assign a number from 1 to 10 , with 10 being the highest level of calm confidence, to describe their calm, confident manner and explain their choice in their own words. A between-group analysis of variance showed that the treatment group had a significantly higher level of selfreported confidence $(p=0.01)$ at a medium effect size. Contrary to popular thinking that numbers have no place in qualitative research, numbers can be appropriate in qualitative research (Sandelowski, 2001); the participants' explanations of the numbers offered meaning. One treatment group participant identified:

[I] felt about a 6; this experience was brand new to me; how-

ever, having just seen a video of the exact situation, I felt much more confident. It provided a general outline of how to respond and what to focus on. Without viewing this beforehand, I probably would have been closer to a 1 or 2 .

Another participant alluded to the differences in the phases and identified the benefits of being an engaged observer, which is another mode of learning in simulation (Seropian, Brown, Gavilanes, \& Driggers, 2004):

I felt calm and confident in caring for Martha on postop[erative] day 1 (maybe a 6 or 7 of 10) because it was more routine, with specific assessments and regulatory checks; however, when she became delirious and confused on postop[erative] day 2, I would have been a little more anxious. It was a great learning experience getting to see how the other group handled the situation though. I was able to see it from an outsider's perspective, and I learned a great deal from this.

\section{Postcare Findings}

Participants completed the postcare questionnaire after caring for real-life perioperative older adult patients 4 weeks after the simulation. The findings revealed few disparities between the treatment and control groups. Participant exposure to other influences in the interim, such as other role models, additional teaching about older adult patients, or reflection, may have equalized the findings. The themes from the postcare dataset included (a) increased awareness, (b) increased confidence, and (c) positive transfer of learning from simulation to real-life practice.

Increased Awareness. The experience of caring for a simulated perioperative older adult translated to heightened aware- 
ness of the care needs of real-life patients. One participant said:

I felt like I had done it before. Even though I felt disorganized and unprepared for my [simulation] scenario, I learned from my mistakes and from the discussions held after each scenario. Overall [the simulation] experience was helpful, especially after looking back after being in clinical.

Another participant noted, "Caring for Martha was an eyeopening experience; [I learned] you can't go in a patient's room, assuming you know what the situation will be like."

Increased Confidence. Regardless of the group (treatment versus control), participants recognized that the confidence gained through the simulated case appeared in various ways when they cared for their real-life patients. One participant revealed:

I felt that I was pretty calm and confident in caring for my patient because I knew going in what her diagnoses were and the possible complications that can occur with her current situation. Complete patient care was the main priority, and through experiencing direct patient care throughout the term, I have become more confident in providing general patient care, such as ambulation, transfers, bathing, feeding, etc. I have become a little better with head-to-toe assessments, which helps me to determine the condition my patient is in at that given time and helps me to prioritize specific care for my patient.

Another participant used his or her experience in simulation to identify where he or she lacked confidence and had learning needs:

I felt confident to take care of the patient. My only hesitation is my lack of experience with assessments. I feel like I am at risk to miss vital assessment clues when it comes to early indicators of complications. I also rate myself lower because even if do pick up on something that is irregular, I am not confident I would be aware of the next step.

Bandura's (1997) concept of mastery modeling supports the idea that guided simulation experiences increase confidence as the individual practices new competencies and then applies them in the clinical setting.

Positive Transfer of Learning From Simulation to Real-Life Practice. Since entry of the use of simulation in health care education, many have questioned its applicability to clinical practice and patient outcomes. Recent research has affirmatively answered the former question but has focused primarily on psychomotor skill transfer, such as surgical techniques and resuscitation skills (Anderson \& Warren, 2011; Hseino et al., 2012), rather than nontechnical skills, such as leadership, communication, and clinical judgment. The review of limited evidence from 2000 to 2011 by Lewis et al. (2012) identified that simulation can be useful for learning nontechnical skills. Although the studies they reviewed had stronger evidence for communication, teamwork, and leadership, studies by others pointed to enhancement of critical thinking related to clinical decision making (Howard, 2007; Ravert, 2004; Schumacher, 2004).

Of those who answered Question 12 (Table, Transfer of Learning), $77 \%$ (86 of 111) responded affirmatively that simulation learning helped them to care for their postoperative patients, and their answers were evenly divided between the control and treatment groups. Moreover, participant responses to other questions offered specific examples to indicate application of their simulation learning. To examine the explanations further, a thematic analysis of the explanations for Question 12 (Transfer of Learning) was performed. Themes included (a) preparation for real-life patients, (b) recognition of enhanced clinical thinking skills, and specifically, (c) prioritization of patient needs.

Preparation for Real-Life Patients. Many of the respondents found that their experiences in simulation facilitated their care of real-life patients. One participant offered that the care of Martha helped because "it provided a safe way to make decisions and not face real-life consequences to the patient." Another stated, "I will be more diligent in my assessments from now on. I didn't [realize] surgical patients were that complicated before."

Recognition of Enhanced Clinical Thinking Skills. Some comments indicated that participants used their simulation learning to think more deeply and carefully about patient care. One participant stated:

I hadn't cared for a surgical patient before this individual so I couldn't be completely confident with it, but learning so much about it [in simulation] helped me understand what I needed to pay attention to.

Another individual was more descriptive in identifying specific geriatric patient care needs from the simulation experience:

It helped [me] become more aware of questioning certain orders of meds [medications] and always double checking them with the Kardex and med[ication] sheet first thing in the morning before your shift. It also made me aware of what to watch for and monitor in an elderly patient who could have a UTI [urinary tract infection]. I know when I was caring for this [real-life] patient, I definitely first thought of that possibility before beginning my care.

One participant identified specific areas of clinical judgment from the simulation that helped to prepare for a real-life patient:

The simulation emphasized noticing first and modifying your plan according to the circumstances presented. Knowledge of working with other patients and various simulations and lab[oratory] activities helped prepare me for his needs.

This observation indicates the value of noticing and the importance of interpreting data before proceeding with a response (Tanner, 2006).

Prioritization of Patient Needs. One important strategy in making clinical judgments is prioritization (Benner et al., 2010; Lasater, 2007a; Tanner, 2006). One participant identified how this simulation experience contributed to the development of care priorities:

During past simulations with caring for a post-surgical patient, I learned about the importance of turn, cough, and deep breathing, so I determined that this was very important for the patient to do in order to help clear her lungs and help her to breathe better. I also learned that splinting of an incision site will help to reduce the pain that is caused by coughing. Pain is also a big factor with postsurgical patients and so I realized that pain management would be a number one priority.

Another participant highlighted the importance of being open to subtle and not-so-subtle changes in patients: 
[The simulation] showed me you never know what to expect with your patients. They may be fine one day, but the next day, they may be extremely confused and irritated. It is important to keep a calm head and to prioritize what is going on.

Another individual indicated, "From simulation, I learned the priorities of postop[erative] patients. I redirected my focus upon entering the room, based on learning from the simulation."

\section{IMPLICATIONS AND RECOMMENDATIONS FOR FURTHER STUDY}

Several implications from the qualitative data are emphasized. Observation of an expert role model and simulation engagement can impact student development of clinical judgment, at least for a period of time, but more research is needed to explore the longer-term effects. For example, participants exposed to the expert nurse role model demonstrated more confidence in their ability to care for their simulated patients. However, differences between the groups diminished in the care of the real-life patients 4 weeks later. The current study did not evaluate patient outcomes, but outcomes are positively linked to development of clinical judgment. Development requires scaffolding of content and clinical experiences_-simulated or otherwise-for competency or mastery to develop (Benner, 1984; Benner et al., 2010; Bransford et al., 2000).

An unexpected finding of this study was the degree to which students perceive that all nurse role models have an impact on their learning; therefore, it is crucial to support clinical preceptors and other contacts with students. However, can expert role models be utilized effectively in simulation to reinforce Bandura's (1997) concept of mastery modeling? Researchers could take the current study another step to determine whether expert role modeling and greater confidence translate to improved patient outcomes.

Other unexpected findings focused on the development of care planning and the assumptions about geriatric patients. Participants in the current study seemed unaware of the bases for care planning. Linking the clinical judgment aspects of noticing and interpreting and, ultimately, responding, requires explicit attention to individual patient needs, as well as deep knowledge of their conditions and understanding of salience. Second, nurses' attention to the unique needs of geriatric patients is critical as the number of aging patients increases. Given a culture that does not value older adults as much as other age groups, nurse educators must help students to apply the same level of clinical judgment for all. Simulation, utilizing collaborative learning strategies such as debriefings conducted as a group, may be an excellent venue for addressing this issue with maximum impact.

Finally, the current study and others indicate that simulation learning transfers to clinical practice. However, questions remain about developing mastery in clinical judgment in simulation for clinical practice, the quality of learning and the length of simulation time required to produce learning that transfers, and the ideal time lapse for application to clinical practice.

\section{CONCLUSION}

The qualitative findings in this article expand on the quantitative findings of Johnson et al. (2012) and raise questions about the link between clinical judgment and confidence, as well as the long-term impact of an expert nurse role model on aspects of clinical judgment. Many participants verified that role models are important to their development of clinical judgment. Although additional study is needed, primarily to ascertain the benefits of simulation to patient outcomes, the qualitative data from this study support the findings that prelicensure students benefit from practicing clinical judgment in the safe environment of simulation and that they carry their learning into practice.

\section{REFERENCES}

Allan, L.J., \& Johnson, J.A. (2008). Undergraduate attitudes toward the elderly: The role of knowledge, contact, and aging anxiety. Educational Gerontology, 35, 1-14. doi:10.1080/03601270802299780

American Association of Colleges of Nursing. (2012). Nursing shortage fact sheet. Retrieved from http://www.aacn.nche.edu/media-relations/ fact-sheets/nursing-shortage

Anderson, J.M., Aylor, M.E., \& Leonard, D.T. (2008). Instructional design dogma: Creating planned learning experiences in simulation. Journal of Critical Care, 23, 595-602. Retrieved from http://dx.doi.org/10.1016/j. jcrc.2008.03.003

Anderson, J.M., \& Warren, J.B. (2011). Using simulation to enhance the acquisition and retention of clinical skills in neonatology. Seminars in Perinatology, 35, 59-67. Retrieved from http://dx.doi.org/10.1053/j. semperi.2011.01.004

Aud, M.A., Bostick, J.E., Marek, K.D., \& McDaniel, R.W. (2006). Introducing baccalaureate student nurses to gerontological nursing. Journal of Professional Nursing, 22, 73-78.

Bambini, D., Washburn, J., \& Perkins, R. (2009). Outcomes of clinical simulation for novice nursing students: Communication, confidence, clinical judgment. Nursing Education Perspectives, 30, 79-82. doi:10.1043/1536-5026-030.002.0079

Bandura, A. (1986). Social foundations of thought and action: A social cognitive theory. Englewood Cliffs, NJ: Prentice Hall.

Bandura. A. (1997). Self-efficacy: The exercise of control. New York, NY: Freeman.

Benner, P. (1984). From novice to expert: Excellence and power in clinical nursing practice. San Francisco, CA: Addison-Wesley.

Benner, P., Sutphen, M., Leonard, V., \& Day, L. (2010). Educating nurses: A call for radical transformation. San Francisco, CA: Jossey-Bass.

Benner, P., Tanner, C., \& Chesla, C. (2009). Expertise in nursing practice: Caring, clinical judgment, and ethics ( $2^{\text {nd }}$ ed.). New York, NY: Springer.

Blum, C.A., Borglund, S., \& Parcells, D. (2010). High-fidelity nursing simulation: Impact on student self-confidence and clinical competence. International Journal of Nursing Education Scholarship, 7, Article 18. doi:10.2202/1548-923X.2035

Bransford, J.D., Brown, A.L., \& Cocking, R.R. (Eds.). (2000). How people learn: Brain, mind, experience, and school. Washington, DC: National Academies Press.

Bremner, M.N., Aduddell, K.F., \& Amason, J.S. (2008). Evidence-based practices related to the human patient simulator and first-year baccalaureate nursing students' anxiety. Online Journal of Nursing Informatics, 12(1). Retrieved from http://ojni.org/12_1/bremner.html

Cant, R.P., \& Cooper, S.J. (2010). Simulation-based learning in nurse education: A systematic review. Journal of Advanced Nursing, 66, 3-15. doi:10.1111/j.1365-2648.2009.05240.x

Cohn, D., \& Taylor, P. (2010). Baby boomers approach age 65-glumly. Retrieved from http://pewresearch.org/pubs/1834/baby-boomers-oldage-downbeat-pessimism

Cordeau, M.A. (2010). The lived experience of clinical simulation of novice nursing students. International Journal for Human Caring, 14(2), 9-15.

Heise, B.A., Johnsen, V., Himes, D., \& Wing, D. (2012). Developing positive attitudes toward geriatric nursing among millennials and generation Xers. Nursing Education Perspectives, 33, 156-161. doi:http://dx.doi. org/10.5480/1536-5026-33.3.156

Howard, V. (2007). A comparison of educational strategies for the acquisition of medical-surgical nursing knowledge and critical thinking skills: Human patient simulator vs. the interactive case study ap- 
proach (Unpublished doctoral dissertation). University of Pittsburgh, Pittsburgh, PA.

Hseino, H., Nugent, E., Lee, M.J., Hill, A.D., Neary, P., Tierney, S., . . Given, M. (2012). Skills transfer after proficiency-based simulation training in superficial femoral artery angioplasty. Simulation in Healthcare, 7, 274 281. doi:10.1097/SIH.0b013e31825b6308

Hsieh, H.F., \& Shannon, S.E. (2005). Three approaches to qualitative content analysis. Qualitative Health Research, 15, 1277-1288. doi:10.1177/1049732305276687

Johnson, E.A., Lasater, K., Hodson-Carlton, K., Siktberg, L., Sideras, S., \& Dillard, N. (2012). Geriatrics in simulation: Role modeling and clinical judgment effect. Nursing Education Perspectives, 33, 176-180.

Kaplan, B., \& Ura, D. (2010). Use of multiple patient simulators to enhance prioritizing and delegating skills for senior nursing students. Journal of Nursing Education, 49, 371-377. doi:10.3928/0148483420100331-07

Koren, M.E., Hertz, J., Munroe, D., Rossetti, J., Robertson, J., Plonczynski, D., . . . Ehrlich Jones, L. (2008). Assessing students' learning needs and attitudes: Considerations for gerontology curriculum planning. Gerontology \& Geriatrics Education, 28(4), 39-56. doi:10.1080/02701960801963029

Lasater, K. (2007a). Clinical judgment development: Using simulation to develop an assessment rubric. Journal of Nursing Education, 46, 496-503.

Lasater, K. (2007b). High-fidelity simulation and the development of clinical judgment: Students' experiences. Journal of Nursing Education, 46, 269-276.

Lasater, K., Johnson, E., Hodson-Carlton, K., Siktberg, L., \& Sideras, S. (2012). A digital toolkit to implement and manage a multisite study. Journal of Nursing Education, 51, 127-132. doi:10.3928/0148483420120113-02

Lewis, R., Strachan, A., \& Smith, M.M. (2012). Is high fidelity simulation the most effective method for the development of non-technical skills in nursing? A review of the current evidence. The Open Nursing Journal, 6, 82-89. doi:10.2174/1874434601206010082
Patton, M.Q. (1999). Enhancing the quality and credibility of qualitative analysis. Health Services Research, 34, 1189-1208.

Phelan, A. (2011). Socially constructing older people: Examining discourses which can shape nurses' understanding and practice. Journal of Advanced Nursing, 67, 893-903. doi:10.1111/j.1365-2648.2010.05536.x

Ravert, P.K.M. (2004). Use of a human patient simulator with undergraduate nursing students: A prototype evaluation of critical thinking and self-efficacy. Dissertation Abstracts International: Section B. Sciences and Engineering, 65(5), 2346.

Rutherford-Hemming, T. (2012). Simulation methodology in nursing education and adult learning theory. Adult Learning, 23, 129-137. doi: $10.1177 / 1045159512452848$

Sandelowski, M. (2001). Real qualitative researchers do not count: The use of numbers in qualitative research. Research in Nursing \& Health, 24, 230- 240 .

Schumacher, L. (2004). The impact of utilizing high-fidelity computer simulation on critical thinking abilities and learning outcomes in undergraduate nursing students (Unpublished doctoral dissertation). Duquesne University, Pittsburgh, PA.

Seropian, MA., Brown, K., Gavilanes, J., \& Driggers, B. (2004). Simulation: Not just a manikin. Journal of Nursing Education, 43, 164-169.

Suliman, W., \& Halabi, J. (2007). Critical thinking, self-esteem, and state anxiety of nursing students. Nurse Education Today, 27, 162-168. Retrieved from http://dx.doi.org/10.1016/j.nedt.2006.04.008

Tanner, C. (2006). Thinking like a nurse: A research-based model of clinical judgment. Journal of Nursing Education, 45, 204-211.

Werner, C.A. (2011). The older population: 2010. 2010 census briefs. Retrieved from http://www.census.gov/prod/cen2010/briefs/c2010br-09.pdf

Wilson, L., \& Fowler, M. (2012). Leadership needed to address the global nursing and midwifery workforce shortage. Nursing Outlook, 60, 51-53. doi:10.1016/j.outlook.2011.11.002

Wurtele, S.K. (2009). "Activities of older adults" survey: Tapping into student views of the elderly. Educational Gerontology, 35, 1026-1031. doi:10.1080/03601270902973557 
Reproduced with permission of the copyright owner. Further reproduction prohibited without permission. 